\title{
Effect of food processing on degradation of hexachlorocyclohexane and its isomers in milk
}

\author{
Sujatha Singh and Krishnaiah Nelapati
}

\author{
Department of Veterinary Public Health and Epidemiology, College of Veterinary Science, P. V. Narsimha Rao Telangana \\ Veterinary University, Rajendranagar, Hyderabad - 500 030, Telangana, India. \\ Corresponding author: Sujatha Singh, e-mail: sujathasingh.hem@gmail.com, \\ Co-author: KN: drnkrishnaiah@gmail.com \\ Received: 02-09-2016, Accepted: 24-01-2017, Published online: 03-03-2017
}

doi: 10.14202/vetworld.2017.270-275 How to cite this article: Singh S, Nelapati K (2017) Effect of food processing on degradation of hexachlorocyclohexane and its isomers in milk, Veterinary World, 10(3): 270-275.

\begin{abstract}
Aim: To study the effect of different food processing techniques on the degradation of organochlorine compounds ( $\alpha, \beta, \gamma$ and $\delta$ hexachlorocyclohexane isomers $(\mathrm{HCH}))$ residues in both natural and fortified samples of milk.

Materials and Methods: Raw milk samples are collected from the local areas of Hyderabad, India. Naturally and fortified milk samples $(\mathrm{HCH})$ were subjected to various food processing techniques, pasteurization $\left(63^{\circ} \mathrm{C}\right.$ for $\left.1 / 2 \mathrm{~h}\right)$, sterilization $\left(121^{\circ} \mathrm{C}\right.$ for $\left.15 \mathrm{~min}\right)$ and boiling for $5 \mathrm{~min}$ and analyzed by gas chromatography with electron capture detector using quick, easy, cheap, effective, rugged and safe method for multiresidue analysis of pesticides in milk with slight modification.

Results: The final mean residual concentration of pesticide in milk after heat processing and percentage of degradation were calculated with respective treatments.
\end{abstract}

Conclusion: Heat treatments are highly effective on reduction of mean residual concentration of $\mathrm{HCH}$ in milk. In which Sterilization and boiling proved to be more effective in degradation of $\mathrm{HCH}$ isomers.

Keywords: gas chromatography-electron capture detector, hexachlorocyclohexane isomers, pesticide residues, quick; easy; cheap; effective; rugged and safe method.

\section{Introduction}

Milk is highly nutritious diet for all age groups including adolescents and patients. The contamination of milk is considered as one of the major public health problems; mainly arise due to biological agents and residues of pesticides, antibiotics, and heavy metals. Injudicious and indiscriminate usage of pesticides, not only contaminate the ecosystem, but also bio-accumulate in the food chain and can be traced in plant and animal tissues causing serious health hazards $[1,2]$. As per World Health Organization (WHO) approximately 20,000 deaths annually were recorded, till now due to pesticide exposures in human population [3], therefore, there is strong need for discussion, on causes of environmental contamination, pesticide residues in milk, meat and other dairy products. The organochlorine (OC) compounds usage has been restricted in agriculture but permitted to use in limited quantities successively for public health activities in controlling vector-borne diseases in most of the developing countries and also in India [4].

In India, $58 \%$ of the population engaged in agriculture, so they are more exposed to the pesticides

Copyright: Singh and Nelapati. Open Access. This article is distributed under the terms of the Creative Commons Attribution 4.0 International License (http://creativecommons.org/licenses/ by/4.0/), which permits unrestricted use, distribution, and reproduction in any medium, provided you give appropriate credit to the original author(s) and the source, provide a link to the Creative Commons license, and indicate if changes were made. The Creative Commons Public Domain Dedication waiver (http:// creativecommons.org/publicdomain/zero/1.0/) applies to the data made available in this article, unless otherwise stated. directly or indirectly. The OC insecticides known to be extremely persistent compounds are either banned or their uses are severely restricted in most of the developed countries in the world [5]. In the recent past, $\gamma$ hexachlorocyclohexane $(\mathrm{HCH})$ (lindane) and technical benzene hexachloride (BHC) (a mixture of $\mathrm{HCH}$ isomers) have been used extensively, particularly for the control of agricultural pests and mosquitoes. The use of the technical grade of $\mathrm{HCH}$ has been banned in India for April 1997, and only lindane can be used for field application on crops. Among various $\mathrm{HCH}$ isomers, only lindane has the insecticidal property and is the only isomer of $\mathrm{HCH}$ which is permitted for use in agriculture [6]. The range of $\mathrm{HCH}$ isomer concentration (as sum of each isomer) is extremely wide $(0.001-4.0 \mathrm{mg} / \mathrm{L})$ in milk and milk products in different countries [7-9]. In India, dairy milk and milk products are highly contaminated with dichlorodiphenyltrichloroethane (DDT) and $\mathrm{HCH}$ isomers for decades $[10,11]$. The OC compounds are known for inducing or aggravating certain health problems in humans such as cancer, immune systems suppression, and the disruption of hormonal functions [12]. Due to lipophilic and relative stable properties of these residues, may easily metabolized in different products and accumulate in fatty tissues of animal (meat, milk, etc.). Continuous intake of contaminated milk and milk products may lead to biomagnification of these residues in the human body, causing chronic toxicity after long-term exposure. To ensure food safety, it is necessary to find simple and cost-effective strategies 
to reduce pesticide residue concentration in the food commodities. Food processing is the best alternative, at domestic and industry level to tackle the current scenario of unsafe food. The adventitious removal of residues by processing is influenced by the type of food, location of pesticide, nature of pesticide, and processing method $[13,14]$. Food processing of livestock products, i.e., cooking, boiling, sterilization, microwave oven cooking, drying, fermentation, and storage processes exhibited large percentage of reduction in residue levels [14-16].

This study was undertaken to study the effect of different food processing methods on degradation of $\mathrm{HCH}$ isomers $(\alpha, \beta, \gamma$ and $\delta \mathrm{HCH})$ in both natural and fortified samples of milk.

\section{Materials and Methods \\ Ethical approval}

No animal was harmed or given stress during collection of milk samples.

\section{Collection of milk samples}

Raw milk samples were collected from local markets of Hyderabad. Later both natural and spiked milk samples $(\alpha, \beta, \gamma$ and $\delta \mathrm{HCH}$ at 1 parts per million $[\mathrm{ppm}]$ ) were processed by adopting quick, easy, cheap, effective, rugged and safe (QuEChERS), AOAC official method 2007.01 with slight modification for analysis of pesticide residues and method was validated with recovery of $70-120 \%$ is the acceptable limit for the analysis of pesticide residues in milk samples on gas chromatography-electron capture detector (GC-ECD).

\section{Chemicals and reagents}

Acetonitrile (ACN), acetone, n-hexane, anhydrous sodium sulfate, sodium acetate, primary secondary amines (PSA) of high-performance liquid chromatography residue grade were obtained from Qualigens and Merck Specialities Private Limited. Analytical standards with $>99 \%$ purity were obtained from Dr. Ehrenstosfer, Germany and stored in deep freeze maintained at $-40^{\circ} \mathrm{C}$.

\section{Pesticide analysis}

Multiresidue pesticide analysis was performed using QuEChERS method with slight modification $[17,18]$. Weigh $15 \mathrm{~g}$ of milk samples with $15 \mathrm{ml}$ of ACN containing $1 \%$ acetic acid followed by addition of $6 \mathrm{~g}$ of anhydrous magnesium sulfate $\left(\mathrm{MgSO}_{4}\right)$ and $1.5 \mathrm{~g}$ of sodium acetate. Shake vigorously for $1 \mathrm{~min}$ by hand. Later centrifuge the tubes at $5000 \mathrm{rpm}$ for $1 \mathrm{~min}$. After centrifugation, $1 \mathrm{ml}$ of ACN extract will be transferred to mini centrifuge tubes for dispersive solid phase extraction, i.e. (d SPE) in which $50 \mathrm{mg}$ of PSA, $50 \mathrm{mg}$ of $\mathrm{C}_{18}$ (octadecylsilane) and $150 \mathrm{mg}$ of anhydrous $\mathrm{MgSO}_{4}$ were added and mixed the extracts for $20 \mathrm{~s}$. The tube was mixed for $30 \mathrm{~s}$ using a vortex mixer and centrifuged again for $5 \mathrm{~min}$ at $3000 \mathrm{rpm}$. Finally, $2 \mathrm{ml}$ of clear extract was collected and evaporated under the gentle stream of nitrogen (15 psi) using Turbovac $\mathrm{LV}$ set at $52^{\circ} \mathrm{C}$ until near dryness up to $20 \mathrm{~min}$. The dried residue content was reconstituted in $1 \mathrm{ml}$ of n-hexane and further analyzed in GC-ECD set under the standard operating conditions (Table-1). In control samples, pure and fortified milk samples with standard mixtures were analyzed using the same protocol. The recovered residue levels from both natural and spiked samples of milk were calculated using following formula.

$$
\begin{aligned}
& \text { Residues in ppm }= \\
& \frac{\text { Sample peak area }}{\text { Standard peak area }} \times \text { concentrated of standard }(\mathrm{ppm})
\end{aligned}
$$

$\times \frac{\mu 1 \text { standard injected }}{\mu l \text { of sample injected }} \times \frac{\begin{array}{c}\text { Final volume of } \\ \text { the sample }(2 \mathrm{ml})\end{array}}{\text { Weight of the sample }}$

\section{Method validation}

The required quantity of $\mathrm{OC}$ compounds of International Standards was prepared from certified reference materials obtained from Dr. Erhenstofer, Germany, and stock standards were obtained from All India Network Project on Pesticide Residue Lab located at Professor Jayashankar Telangana State Agricultural University, Rajendranagar, Hyderabad, Telangana, India. The beta-endosulfan standard was fortified in the representative samples of milk at the rate of $0.1 \mathrm{ppm}$. The recovery of pesticide residues above $70-120 \%$ is considered, as the acceptable limit. The pattern of elution of beta-endosulfan standards (Figure-1) was analyzed on the basis of specific retention time for GC-ECD. The limit of detection and limit of quantification of specific OC compounds were $0.01 \mathrm{ppm}$ and $0.05 \mathrm{ppm}$, respectively. The recovery value was calculated from the calibration curves constructed from the concentration and peak areas of the obtained chromatograms from the milk samples (Figure-2) with standards of OC pesticide. Blank analysis of milk samples was also performed to check the different matrix interferences.

\section{Statistical analysis}

The procedure was run thrice with each sample 10 in numbers were analyzed statistically through one-way ANOVA using SPSS software.

\begin{tabular}{|c|c|}
\hline GC column & $\begin{array}{l}\text { Zebron-ZB - 50, } \\
\text { length - } 30 \mathrm{~m}, 0.25 \mu \mathrm{m} \text { film } \\
\text { thickness, internal diameter } \\
0.25 \mathrm{~mm}\end{array}$ \\
\hline Column oven $\left({ }^{\circ} \mathrm{C}\right)$ & $280^{\circ} \mathrm{C}$ \\
\hline Detector temperature & $300^{\circ} \mathrm{C}$ \\
\hline Injector temperature & $260^{\circ} \mathrm{C}$ \\
\hline Injector status & $\begin{array}{l}\text { Font injector type split, split } \\
\text { ratio } 1: 10\end{array}$ \\
\hline Carrier gas flow $(\mathrm{ml} / \mathrm{min})$ & $12.4 \mathrm{ml} / \mathrm{min}$ \\
\hline Total run time (min) & $60 \mathrm{~min}$ \\
\hline
\end{tabular}

Table-1: GC operating conditions.

$\mathrm{GC}=$ Gas chromotography 


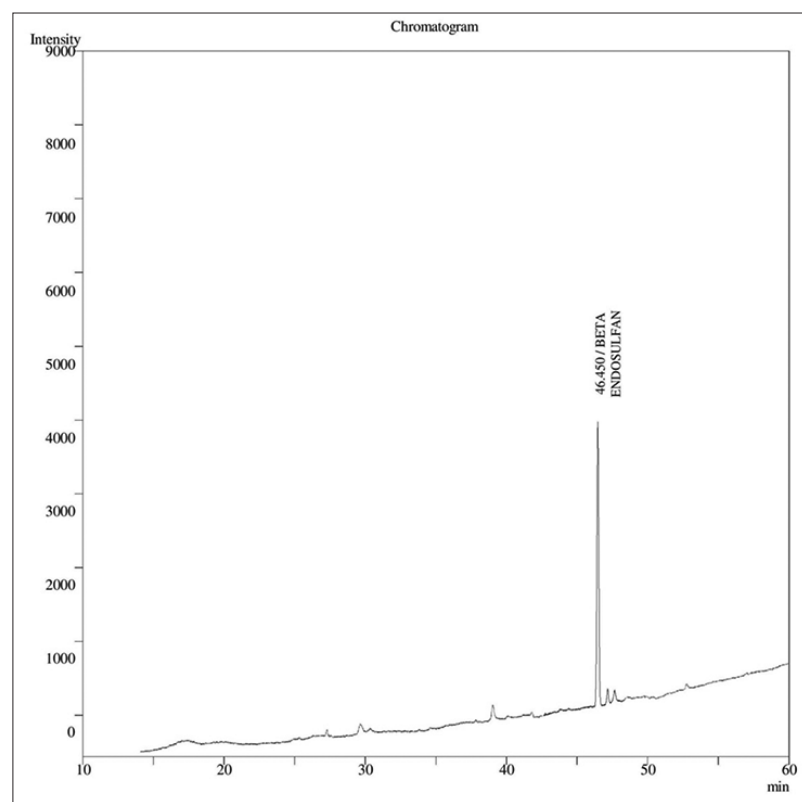

Figure-1: Chromatogram representing elution pattern of beta endosulfan standard.

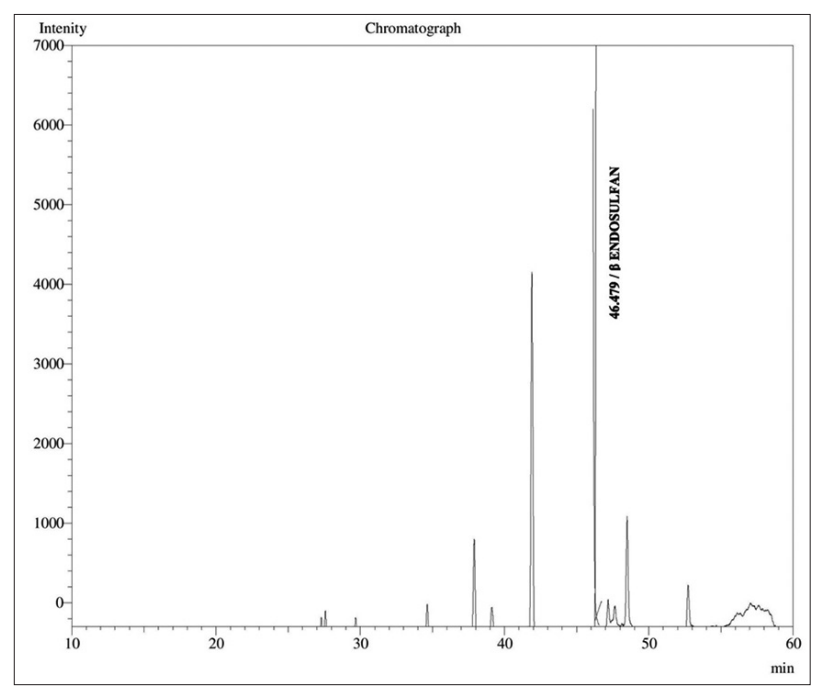

Figure-2: Chromatogram representing the elution pattern of beta endosulfan in fortified milk.

\section{Results}

The mean residual levels and percentage of degradation of $\mathrm{OC}$ compounds after heat processing in both natural and spiked milk samples were presented in Table-2. Residual levels of $\alpha \mathrm{HCH}$ content in natural raw milk was $0.0460 \mathrm{ppm}$, degraded to $0.0375,0.0150$ and $0.0275 \mathrm{ppm}$ accounting $18.47 \%, 45.65 \%$ and $40.21 \%$ of degradation after pasteurization, boiling and sterilization, respectively. In the spiked (1 ppm) raw milk, the initial concentration was $1.11 \mathrm{ppm}$ which has been degraded to $0.895,0.3587$ and 0.4377 ppm accounting $19.36 \%, 76.69 \%$ and $60.56 \%$ reductions, respectively. The content of $\alpha \mathrm{HCH}$ in raw and spiked milk was differed significantly among the treatments. The processing methods, i.e., boiling and sterilization did not differed significantly in natural samples, whereas in spiked milk, the residual content was differed significantly $(\mathrm{p}<0.01)$ among the treatments. The $\beta \mathrm{HCH}$ content in natural raw milk was $0.0634 \mathrm{ppm}$, degraded during heat processing reaching $0.0532 \mathrm{ppm}$ in pasteurized milk, $0.0398 \mathrm{ppm}$ in boiled and $0.0235 \mathrm{ppm}$ in sterilized milk, accounting $16.08 \%, 37.22 \%$ and $62.93 \%$, respectively. In the spiked (1 ppm) raw milk, the initial concentration of $\beta \mathrm{HCH}$ was $0.785 \mathrm{ppm}$, degraded to 0.6712 in pasteurized, 0.4444 in boiled and $0.2745 \mathrm{ppm}$ in sterilized milk accounting to $14.49 \%, 43.38 \%$ and $65.03 \%$ reductions, respectively. The content of $\beta \mathrm{HCH}$ in raw and spiked milk was differed significantly $(\mathrm{p}<0.01)$ among the treatments in both natural and spiked milk samples.

The $\gamma \mathrm{HCH}$ content in natural raw milk was $0.0158 \mathrm{ppm}$, degraded during heat processing reaching $0.0140 \mathrm{ppm}$ in pasteurized milk and $0.0115 \mathrm{ppm}$ in boiled, accounting 11.39 and $27.21 \%$ of degradation, respectively, whereas it was below detectable level after sterilization. In the spiked (1 ppm) raw milk, it was $0.756 \mathrm{ppm}$, degraded to 0.5676 in pasteurized milk, $0.3605 \mathrm{ppm}$ in boiled milk and $0.2883 \mathrm{ppm}$ in sterilized milk accounting $24.92 \%, 52.31 \%$ and $61.86 \%$ reductions, respectively. The content of $\gamma \mathrm{HCH}$ in raw and spiked milk differed significantly with the treatments, and all the treatments differed significantly $(\mathrm{p}<0.01)$ among themselves.

The $\delta \mathrm{HCH}$ content in natural raw milk was $0.4732 \mathrm{ppm}$, reduced after heat processing reaching $0.4327 \mathrm{ppm}$ in pasteurized milk, $0.312 \mathrm{ppm}$ in boiled, $0.256 \mathrm{ppm}$ in sterilized milk accounting $8.5 \%$, $34.06 \%$ and $45.90 \%$ reductions, respectively. In the spiked (1 ppm) raw milk, it was $0.854 \mathrm{ppm}$, degraded to $0.745 \mathrm{ppm}$ in pasteurized milk, $0.355 \mathrm{ppm}$ in boiled milk and $0.254 \mathrm{ppm}$ in sterilized milk accounting $11.70 \%, 58.43 \%$ and $70.25 \%$ reductions, respectively. In natural and spiked milk samples, the residue levels differed significantly $(\mathrm{p}<0.01)$ and also among the three treatments.

The total $\mathrm{HCH}$ content in natural raw milk was $0.5984 \mathrm{ppm}$, reduced to $0.5374 \mathrm{ppm}$ in pasteurized milk, $0.3737 \mathrm{ppm}$ in boiled, $0.307 \mathrm{ppm}$ in sterilized milk accounting $10.19 \%, 37.55 \%$ and $48.69 \%$, respectively. In the spiked (1 ppm) raw milk, the total $\mathrm{HCH}$ was $3.505 \mathrm{ppm}$, degraded to $2.878 \mathrm{ppm}$ in pasteurized milk, $1.618 \mathrm{ppm}$ in boiled milk and $1.221 \mathrm{ppm}$ in sterilized milk accounting $17.88 \%, 66.85 \%$ and $65.16 \%$ reductions, respectively. In natural and spiked milk samples, the residue levels differed significantly $(p<0.01)$ within treatments, whereas in spiked milk boiling and sterilization treatments did not differ significantly.

\section{Discussion}

During food processing the pesticide on the basis of individual nature, may degrade in different ways, such as it may evaporate, thermally degrade or co-distillate accordingly [16]. Food processing studies are very important, to relate the levels of residue 
Table-2: Residual levels of organochlorine compounds after heat processing in milk.

\begin{tabular}{|c|c|c|c|c|c|c|c|}
\hline $\begin{array}{l}\text { Name of the } \\
\text { pesticide }\end{array}$ & Raw milk (ppm) & $\begin{array}{c}\text { Pasteurization } \\
(\mathrm{ppm})\end{array}$ & $\operatorname{Deg}(\%)$ & Boiling (ppm) & $\operatorname{Deg}(\%)$ & $\begin{array}{l}\text { Sterilization } \\
(\mathrm{ppm})\end{array}$ & $\operatorname{Deg}(\%)$ \\
\hline \multicolumn{8}{|l|}{ a $\mathrm{HCH}$} \\
\hline Natural & $0.0460 \pm 0.005^{\mathrm{a}}$ & $0.0375 \pm 0.003^{b}$ & 18.47 & $0.0150 \pm 0.0025^{c}$ & 45.65 & $0.0275 \pm 0.002^{c}$ & 40.21 \\
\hline Spiked & $1.11 \pm 0.023^{a}$ & $0.895 \pm 0.019^{b}$ & 19.36 & $0.3587 \pm 0.002^{\mathrm{d}}$ & 76.69 & $0.4377 \pm 0.013^{c}$ & 60.56 \\
\hline \multicolumn{8}{|l|}{$\beta \mathrm{HCH}$} \\
\hline Natural & $0.0634 \pm 0.003^{\mathrm{a}}$ & $0.0532 \pm 0.025^{b}$ & 16.08 & $0.0398 \pm 0.021^{c}$ & 37.22 & $0.0235 \pm 0.012^{\mathrm{d}}$ & 62.93 \\
\hline Spiked & $0.785 \pm 0.05^{\mathrm{a}}$ & $0.6712 \pm 0.039^{b}$ & 14.49 & $0.4444 \pm 0.006^{c}$ & 43.38 & $0.2745 \pm 0.010^{d}$ & 65.03 \\
\hline \multicolumn{8}{|l|}{ y $\mathrm{HCH}$} \\
\hline Natural & $0.0158 \pm 0.002^{\mathrm{a}}$ & $0.0140 \pm 0.002^{b}$ & 11.39 & $0.0115 \pm 0.03^{c}$ & 27.21 & BDL & - \\
\hline Spiked & $0.756 \pm 0.05^{\mathrm{a}}$ & $0.5676 \pm 0.024^{b}$ & 24.92 & $0.3605 \pm 0.016^{c}$ & 52.31 & $0.2883 \pm 0.019^{d}$ & 61.86 \\
\hline \multicolumn{8}{|l|}{$\delta \mathrm{HCH}$} \\
\hline Natural & $0.4732 \pm 0.04^{a}$ & $0.4327 \pm 0.014^{b}$ & 8.5 & $0.312 \pm 0.015^{c}$ & 34.06 & $0.256 \pm 0.012^{\mathrm{d}}$ & 45.90 \\
\hline Spiked & $0.854 \pm 0.06^{a}$ & $0.745 \pm 0.058^{\mathrm{b}}$ & 11.70 & $0.355 \pm 0.014^{c}$ & 58.43 & $0.254 \pm 0.014^{d}$ & 70.25 \\
\hline \multicolumn{8}{|l|}{ Total HCH } \\
\hline Natural & $0.5984 \pm 0.032^{\mathrm{a}}$ & $0.5374 \pm 0.017^{b}$ & 10.19 & $0.3737 \pm 0.016^{c}$ & 37.55 & $0.307 \pm 0.018^{d}$ & 48.69 \\
\hline Spiked & $3.505 \pm 0.65^{a}$ & $2.878 \pm 0.51^{\mathrm{b}}$ & 17.88 & $1.618 \pm 0.22^{c}$ & 66.85 & $1.221 \pm 0.21^{c}$ & 65.16 \\
\hline
\end{tabular}

Residual levels bearing different superscripts $(a, b, c$, and $d)$ horizontally differed significantly $(p<0.01)$.

$\mathrm{HCH}=\mathrm{Hexachlorocyclohexane}$

concentration in raw food commodities to the level of processed food products, to evaluate the strength of processing factor in degradation of various pesticide in the products [19]. Most of the OC compounds and its metabolites are lipid soluble, and thus they found more concentrated in the fatty portions of foods especially in butter, cream ghee and cheeses, etc. $[10,20]$. The percentage of degradation in both natural and spiked samples of milk was $(18.47 \%$ and $19.36 \%$ for $\alpha \mathrm{HCH}),(16.08 \%$ and $14.49 \%$ for $\beta \mathrm{HCH})$, $(11.39 \%$ and $24.92 \%$ for $\gamma \mathrm{HCH}),(8.5 \%$ and $11.70 \%$ for $\delta \mathrm{HCH}$ ), and (total $\mathrm{HCH} 10.19 \%$ and $17.88 \%$ ), respectively, on pasteurization. Pasteurization could not eliminate the residues in the milk, but degraded to some extent which was similar to $15.38 \%$ of degradation [7] whereas very little effect of pasteurization seen on the degradation levels of hexachlorobenzene (HCB) and lindane content in milk samples [21] whereas some scientist reported that HCB pesticide residue remained unaffected by pasteurization [22]. The percentages of degradation in both natural and spiked samples of milk were $45.65 \%$ and $76.69 \%$, $37.22 \%$ and $43.38 \%, 27.21 \%$ and $52.31 \%, 34.06 \%$ and $58.43 \%, 37.55 \%$ and $66.85 \%$, respectively, for $\alpha$, $\beta, \gamma$ and $\delta \mathrm{HCH}$. During boiling, the milk samples were subjected to higher temperature where considerable decrease in residue levels in all isomers of $\mathrm{HCH}$ were recorded, while in $\beta \mathrm{HCH}$ degradation was less compared to other isomers of $\mathrm{HCH}$ in spiked samples, as by the physiochemical nature of $\beta \mathrm{HCH}$ have lower volatility and high melting point, makes more stable compound than rest of the isomers of $\mathrm{HCH}$ [23]. The percentage of degradation of $24.49 \%$ was seen in $\beta \mathrm{HCH}$ content on boiling, which was less than the present study [24]. Skim milk recombined with butter oil fortified with $2 \mathrm{ppm} \mathrm{HCH}$ shown very little impact of boiling and boiling with malai removal reduced the $\mathrm{HCH}$ isomers by $11.54-26.78 \%$ and 35.86-50.88\% [25]. Boiling for 5, 10, and $15 \mathrm{~min}$ reduced the lindane levels by $75.0 \%, 79.6 \%$ and $85.4 \%$, respectively [26]. Spiked samples of milk with lindane subjected to boiling for $2 \mathrm{~min}$ and reported that boiling was more effective in dissipation of pesticide residues [27]. The percentage of degradations in both natural and spiked samples of milk on sterilization were 40.21 and 60.56 for $\alpha \mathrm{HCH}, 62.93$ and 65.03 for $\beta \mathrm{HCH}, 61.86$ for $\gamma \mathrm{HCH}, 45.90$ and 70.25 for $\delta \mathrm{HCH}$ and 48.69 and 65.16 for total $\mathrm{HCH}$, respectively. Sterilization of milk at $12^{\circ} \mathrm{C}$ for $15 \mathrm{~min}$. showed $83.25 \%, 91.67 \%$ and $68.70 \%$ loss in $\beta$ BHC, lindane and p,p' DDT content, respectively [28]. Skim milk recombined with butter oil fortified with $2 \mathrm{ppm} \mathrm{HCH}$ on sterilization, there was 19\% of degradation in the HCH content [29]. The effect of sterilization on the residues of lindane and its metabolites contaminated at the level of $1 \mathrm{mg} / \mathrm{kg}$ fat, observed to reduce the residual content by $84.4 \%$ and $76.6 \%$, respectively [26].

\section{Conclusion}

The $\mathrm{HCH}$ residues were detected in the milk samples, which exceeded the maximum residue level limits $(0.001 \mathrm{ppm})$, recommended by FAO/WHO. Effect of different food processing plays an efficient role on degradation of OC compound residues in milk. Most of the residues, which are highly lipophilic nature, are hardly get metabolized, hence it may easily concentrate in milk products leading to bioaccumulation and biomagnification [30]. Prolonged consumption of contaminated milk will severely affect the human health and responsible for producing chronic effects like cancer and risk of Alzheimer's disease [31]. Application pesticide in enhancing agricultural productivity must be balanced against possible health hazards arising from toxic pesticide residues in food. First and foremost thing is application pesticide should be in compliance with Good Agricultural Practices and shifting from chemical farming to organic farming. However, 
in developing countries like India, the process of adoption of good agricultural practices and organic farming is very slow; meanwhile, it is highly practical to adopt some simple processing techniques and acquire significance for reducing the harmful pesticide residues in food.

\section{Authors' Contributions}

The study was part of SS's research work during the Ph.D. program. SS prepared, processed and analyzed the samples. KN designed and planned the research programme and approved the final manuscript.

\section{Acknowledgments}

The authors are highly thankful to All India Network Project on Pesticide Residues (ICAR-RES/2009-10/1) for financial help. Professor Jayashankar, Telangana State Agricultural University, Rajendranagar, and the Dean, College of Veterinary Science, Rajendranagar, for providing necessary infrastructure facilities in carrying out the research work.

\section{Competing Interests} interests.

The authors declare that they have no competing

\section{References}

1. Coat, S., Monti, D., Legendre, P., Bouchon, C., Massat, F. and Lepoint, G. (2011) Organochlorine pollution in tropical rivers (Guadeloupe): Role of ecological factors in food web bioaccumulation. Environ. Pollut., 159(6): 1692-1701.

2. Borgå, K., Gabrielsen, G.W. and Skaare, J.U. (2001) Biomagnification of organochlorines along a Barents Sea food chain. Environ. Pollut., 113(2): 187-198.

3. WHO, Joint, and FAO Expert Consultation. (1990) Diet, Nutrition and the Prevention of Chronic Diseases. WHO, Geneva.

4. Jadhav, V.J. and Waskar, V.S (2011) Public health implications of pesticide residues in meat. Vet. World, 4(4): 178-182.

5. Battu, R.S., Singh, B. and Kang, B.K. (2004) Contamination of liquid milk and butter with pesticide residues in the Ludhiana district of Punjab state, India. Ectotoxicol. Environ. Saf., 59(3): 324-331.

6. Walker, K., Vallero, D.A. and Lewis, R.G. (1999) Factors influencing the distribution of lindane and other hexachlorocyclohexanes in the environment. Environ. Sci. Technol., 33: 4373-4378.

7. Kampire, E., Kiremire, B.T., Nyanzi, S.A. and Kishimba, M. (2011) Organochlorine pesticide in fresh and pasteurized cow's milk from Kampala markets. Chemosphere, 84(7): 923-927.

8. Luzardo, O.P., Almeida-González, M., HenríquezHernández, L.A., Zumbado, M., Álvarez-León, E.E. and Boada, L.D. (2012) Polychlorobiphenyls and organochlorine pesticides in conventional and organic brands of milk: Occurrence and dietary intake in the population of the Canary Islands (Spain). Chemosphere, 88: 307-315.

9. Georgescu, B., Georgescu, C., Daraban, S. and Mihaiescu, T. (2011) Assessment of persistent organic pollutants acting as endocrine disruptor chemicals in animal fat, cow milk and lacteous sub-products from Cluj Country, Romania. Anim. Biol. Anim. Husb., 3: 1-9.

10. Pandit, G.G., Sharma, S., Srivastava, P.K. and Sahu, S.K.
(2002) Persistent organochlorine pesticide residues in milk and dairy products in India. Food Addit. Contam., 19(2): 153-157.

11. Negi, R.K. and Rani, S. (2015) Contamination profile of DDT and $\mathrm{HCH}$ in packaged milk samples collected from Haridwar, India. Int. J. Pure Appl. Biosci., 3(5): 121-127.

12. Vincenzo, R.M., Campanella, L. and Avino, P. (2006) Determination of organophosphorus pesticide residues in human tissues by capillary gas chromatography - Negative chemical ionization mass spectrometry analysis. J. Chromatogr. B, 780: 431-441.

13. Keikotlhaile, B.M., Spanoghe, P. and Steurbaut, W. (2010) Effects of food processing on pesticide residues in fruits and vegetables: A meta-analysis approach. Food Chem. Toxicol., 48(1): 1-6.

14. Bajwa, U. and Sandhu, K.S. (2014) Effect of handling and processing on pesticide residues in food - A review. J. Food Sci. Technol., 51(2): 201-220.

15. Regueiro, J., López-Fernández, O., Rial-Otero, R., Cancho-Grande, B. and Simal-Gándara, J. (2015) A review on the fermentation of foods and the residues of pesticides - Biotransformation of pesticides and effects on fermentation and food quality. Crit. Rev. Food Sci. Nutr., 55(6): 839-863.

16. Kaushik, G., Satya, S. and Naik, S.N. (2009) Food processing a tool to pesticide residue dissipation - A review. Food Res. Int., 42(1): 26-40.

17. Lehotay, S.J., Mastovska, K. and Yun, S.J. (2005) Evaluation of two fast and easy methods for pesticide residue analysis in fatty food matrixes. JAOAC Int., 88(2): 630-638.

18. Jeong, I.S., Kwak, B.M., Ahn, J.H. and Jeong, S.H. (2012) Determination of pesticide residues in milk using a QuEChERS-based method developed by response surface methodology. Food Chem., 133(2): 473-481.

19. Gonzalez-Rodriguez, R.M., Rial-Otero, R., Cancho-Grande, B., Gonzalez-Barreiro, C. and SimalGándara, J. (2011) A review on the fate of pesticides during the processes within the food-production chain. Crit. Rev. Food Sci. Nutr., 51(2): 99-114.

20. Bayat, S., Sari, A.E., Bahramifar, N., Younesi, H. and Behrooz, R.D. (2011) Survey of organochlorine pesticides and polychlorinated biphenyls in commercial pasteurized milk in Iran. Environ. Monit. Assess., 175(1-4): 469-474.

21. Donia, M.A., Abou-Arab, A.A.K., Enb, A., El-Senaity, M.H. and Abd-Rabou, N.S. (2010) Chemical composition of raw milk and the accumulation of pesticide residues in milk products. Glob. Vet., 4(1): 6-14

22. Pietrino, D. (1991) Pesticide residues and milk processing. Ind. Latte, 27: 3-32.

23. POPRC. (2007) UNEP/POPS/POPRC.3/20/Add.5; Stockholm Convention on Persistent Organic Pollutants.

24. Ismail, T. and Elkassas, W.M. (2016) Prevalence of some pesticides residues in buffalo's milk with refer to impact of heating. Alex. J. Vet. Sci., 48(2): 113-123.

25. Madan, V.K. and Kathpal, T.S. (2001) Decontamination of Pesticide Residues in Milk by Different Kitchen Processes. International Conference Pesticide, Environment, Food Security. IARI, New Delhi. p267-268.

26. Abou-Arab, A.A.K. (1999) Effects of processing and storage of dairy products on lindane residues and metabolites. Food Chem., 64: 467-473.

27. Dhiman, N., Bakhshi, A.K., Singh, B. and Gagan, J. (2005) Effect of conventional household processes on chlorpyrios and lindane residues in milk. Pestic. Res. J., 17(2): 104-106.

28. Abou-Arab, A.A.K. (1991) Microbiological and Compositional Quality of Dairy Products in Relation to Some Pollutants, Ph.D. Faculty of Agriculture Ain Shams University.

29. Nath, B.S., Unnikrishnan, V., Bhavadasan, M.K., Chitra, P.S. and Murthy, M.K.R. (1997) Effect of processing on some organochlorine pesticide contents of milk and milk 
products. Indian J. Dairy Biosci., 8: 6-9.

30. Darko, G. and Acquaah, S.O. (2008) Levels of organochlorine pesticides residues in dairy products in Kumasi, Ghana. Chemosphere, 71(2): 294-298.
31. Singh, N.K., Chhillar, N., Banerjee, B.D., Bala, K., Basu, M. and Mustafa, M. (2013) Organochlorine pesticide levels and risk of Alzheimer's disease in North Indian population. Hum. Exp. Toxicol., 32(1): 24-30.

$* * * * * * * *$ 